\title{
Yaşlılık ve Sağlıkta Eşitsizlikler
}

\section{Elderly and Inequalities in Health}

\section{Sait SÖNMEZ[1] Celalettin ÇEVİK[2]}

Sağlık hiçbir ayrım olmaksızın herkesin temel bir insan hakkıdır. Yașlanan dünya nüfusu içinde yașlılar eșitsizlikler bakımından kırılgan gruplardan biridir. 2019 yılında yaşlı nüfusun oranı dünyada 1 milyar olmuş olup bu sayı 2030'da 1,4 milyara, 2050'de 2,1 milyara yükseleceği öngörülmektedir. Demografik dönüşüm ve yaşlı popülasyondaki artış kronik hastalıkları da beraberinde getirmekte, sağlık harcamalarını artırmakta, yaşlıların öz yeterliliklerini ve yaşam kalitelerini ise azaltmaktadır. Bakım gereksinimlerindeki artış, aile yapısının değişimi, huzurevleri ve bakım evlerinin kapasitesini de aşmaktadır. Dolayısıyla kırılgan bir grup olan yaşlıların nitelikli, hakkaniyetli bir bakım alması, sağlıkta eşitsizliklerin olumsuz etkilerinden yalıtılmış olmaları gereklidir. Nitekim sağlıkta eşitsizlikler, yașlılarda hastalık ve ölümlerin artışına neden olduğu gibi yaşlıların yaşam kalitesini de olumsuz etkilemektedir. İleri yaşlarda görülen eşitsizlikler tesadüfi olmayıp önemli bir kısmı insanların fiziksel ve sosyal ortamlarından ve bu ortamların sağlık davranışları üzerindeki etkilerinden kaynaklanmakta, çevre, içine doğulan aile, cinsiyet ve etnik köken gibi kişisel özelliklerin etkisiyle kümülatif eşitsizliklere yol açmaktadır. Yaşlıların maruz kaldığı eşitsizlikler özellikle COVID-19 pandemisi döneminde etkisini artırmıştır. Yaşlılar izole oldukları gibi, sosyal yönden de önemli ölçüde sınırlanmış, mental sorunlar da artmıştır. Artan yașlı nüfusla birlikte bulaşıcı olmayan hastalıkların artışı, yaşlılara yönelik sağlık ve sosyal hizmet sunumuna bașat bir rol vermiştir. Bu nedenle yaşlıların sağlıklarını koruyup geliştirebilmek için geliştirilmiş, kapsamlı, birinci basamak destekli yaşlı sağlığı politikalarına gereksinim vardır. Yaşlılar düşünülerek uygun yaşam alanları oluşturulmalı, toplumda sınıfsal farklılıkların etkileri ortadan kaldırılmalı, sosyal devlet yapısı güçlendirilmelidir.

Anahtar Kelimeler: yaşlılık, sağlıkta eşitsizlikler, yaşlı sağlı̆̆ı sorunları

Health is a basic human right of everyone without any discrimination. Among the aging world population, the elderly are one of the vulnerable groups in terms of inequalities. The proportion of the elderly population in the world was 1 billion in 2019 and this number is expected to increase to 1.4 billion in 2030 and 2.1 billion in 2050. Demographic transformation and the increase in the elderly population bring chronic diseases, increase health expenditures, and decrease the self-efficacy and quality of life of the elderly. The increase in care needs, the change in family structure, and nursing homes exceed the capacity of nursing homes. Therefore, it is necessary for the elderly, who are a vulnerable group, to receive qualified and equitable care and to be isolated from the negative effects of health inequalities. As a matter of fact, inequalities in health cause an increase in morbidity and mortality in the elderly, as well as negatively affecting the quality of life of the elderly. The inequalities seen in older ages are not accidental, but a significant part of them is caused by the physical and social environments of people and the effects of these environments on their health behaviors, leading to cumulative inequalities with the effect of personal characteristics such as the environment, the family they were born into, gender and ethnicity. The inequalities that the elderly are exposed to have increased their impact especially during the COVID-19 pandemic. The elderly are not only isolated, but also socially limited, and their mental problems have increased. The increase in non-communicable diseases with the increasing elderly population has given a dominant role to the provision of health and social services for the elderly. For this reason, there is a need for comprehensive, primary care supported elderly health policies in order to protect and improve the health of the elderly. Appropriate living spaces should be created by considering the elderly, the effects of class differences in society should be eliminated, the social state structure should be strengthened Keywords: old age, inequalities in health, elderly health problems

Keywords: old age, health inequalities, elderly health problems 


\section{GíRiş}

ağlık din, dil, ırk, cinsiyet gibi herhangi bir ayrım gözetmeksizin temel bir insan hakkıdır. Ancak hem ülkeler, hem de bölgeler arasında başlıca sosyal belirleyiciler nedeniyle sağlıkta eşitsizlikler görülmektedir (Petrovic vd., 2018). Dünya Sağlık Örgütü'ne (DSÖ) göre sağlıkta eşitsizlik "Yalnızca gereksiz ve önlenebilir değil aynı zamanda haksız ve adaletli olmayan farklılıklardır" (World Health Organization, 2021b). Sağlıkta eşitsizliklerin başlıca sosyal belirleyicileri sınıf, eğitim düzeyi, gelir ve meslek olup sağlığın sosyal belirleyicilerinin yanı sıra konjonktürel değişiklikler, sağlık sistemi, pandemi gibi olağanüstü durumlar da sağlıkta eşitsizliklerin oluşumuna çanak tutmaktadır (Pickersgill, 2020). Sağlıkta eşitsizliklerin etkileri çocuk, kadın, engelli, göçmen ve yaşlı gruplarında çok daha belirgin olup dezavantajlı bu grupların karşı karşıya oldukları hastalık ve ölüme ilişkin çıktılar toplumu da etkilemektedir (Marmot, 2017).

Son yıllarda başlıca doğurganlığın, ölümlerin azalmasına bağlı olarak doğuşta beklenen yaşam süresi artmış ve dünya genelinde yaşlı nüfusta bir artış söz konusu olmaya başlamıştır (World Health Organization, 2021a). Aynı durum Türkiye için de geçerli olup Türkiye'de doğuşta beklenen yaşam süresi son yıllarda önemli ölçüde artış göstererek ortalama 78.6 yıl olmuştur (TUIK, 2021). Türkiye Nüfus Sağlık Araştırması (TNSA) 2018 verisine göre de Türkiye'de nüfusun \%10'unu altmış beş yaş ve üzeri kişiler oluşturmaktadır (TNSA, 2018). Birçok yaşlının genel anlamda sağlıkları iyi olsa da yaşlanma süreciyle birlikte sağlık algıları kötüleşmeye başlar, öte yandan yaşlılar yaşlı olmayanlara kıyasla daha fazla sağlı hizmet gereksinimleri olsa da uygun, ücretsiz / karşılanabilir bir ücrete ve kaliteli sağlık hizmetine erişmede diğer gruplara kıyasla dezavantajlıdırlar (United Nations, 2021). Yaşlanma fizyolojik, psikolojik değişiklikleri içeren bir süreç olup aynı zamanda dış risklere maruz kalmasının birikmiş etkileri, izolasyon ve yaşlının sevdiklerinin kaybı gibi sosyal değişiklikler de yaşlıyı daha fazla etkileyebilir. Genetiğin, hava kirliliğinin ve erişilebilirliğin, sigara ve hareketsizlik gibi riskli davranışların, meslek, gelir düzeyi, eğitim gibi bireysel özelliklerin yaşlılıkta sağlık ve işlevlerdeki olumsuz durumu yaklaşık \%25'inden sorumlu olduğu tahmin edilmektedir (World Health Organization, 2018). Ayrıca, bu çevresel ve bireysel faktörler iç içe olup sağlık ve diğer alanlardaki yaşlılık eşitsizlikleri, kişinin konumu, cinsiyeti ve sosyo-ekonomik durumu, sağlık ve sosyal güvenlik haklarıyla ilgili eksik veya yetersiz mevzuat ve politikalar biriken dezavantajlara neden olur.

\section{Dünyada ve Türkiye'de Yaşlılık}

Yaşlılık, insanların sahip olduğu ruhsal ve fiziksel bazı yetileri zaman içerisinde azaltan fizyolojik bir olaydır (Kuzu vd., 2019). DSÖ altmış beş yaşı yaşlılık döneminin başı olarak belirlemiştir ve kendi içinde yaşlılık genç yaşlı (65-74), yaşlı (75-84) ve ileri yaşlı (85+) olmak 
üzere üç sınıfta irdelenmektedir. Altmış beş yaş üstü grubun yüzdesine göre de toplum; genç toplum (\%4 ve altı), olgun toplum (\%4-7 arası), yaşlı toplum (\%7-10 arası) ve çok yaşlı (\%10 ve üzeri) olarak dört gruba ayrılmaktadır. 2019 yılında yaşlı popülasyon yaklaşık 1 milyar kişiden oluşmakta olup bu sayının 2030 yılında 1.4 milyara, 2050 yılında ise 2.1 milyara yükseleceği öngörülmektedir (World Health Organization, 2021a). Bu artışın hızla gerçekleşeceği ve önümüzdeki on yıllarda, özellikle gelişmekte olan ülkelerde hızlanması beklenmektedir. Antik çağ döneminde her 100 bireyden sadece biri 60 yaşına ulaşabilirken ve Romalı bir askerin ortalama 22 yll ömrü varken, 20. Yüzylla gelene kadar çoğu ülkede uzun yaşam için gerekli uygun ortamın olmadığı görülmektedir. Bu dönemlerde Avrupa'ya bakıldığında ortalama ömrün 50'li yaşlar olduğu, erken yaş ölümlerinin olduğu, iyi şartlarda yaşlılık dönemine erişenlerin ise sadece kral, yöneticiler, yüksek rütbe askerler gibi kısaca üst sosyal sınıfın olduğu bildirilmektedir (Tufan, 2016).

Modern tıpta yaşanan gelişmeler, sağlık hizmetlerine erişim gibi gelişmeler sonucu azalmakta olan ölüm hızları, doğurganlık hızındaki azalmalar dolayısıyla erişkin nüfusun altmış beş yaş düzeyine erişmeye başlaması yaşlı nüfusun payını artırmaktadır. Küresel nüfustaki bu önemli değişim nedeniyle, başta sağlık ve sosyal hizmetler, şehir planlaması, konut, ulaşım gibi alanlarda yaşlılara özgü acil yapılandırmalar gerekmektedir. Çağımızda sosyal, ekonomik vb. pek çok yönden değiş̧imler sonucu ortalama ömür artmış ve hala artmaya devam etmektedir (Arun, 2015).

Yaşlılık bakımından bir başka önemli nokta da ülkelerin yaşlı nüfus oranların artış hızıdır. Nitekim gelişmekte olan ülkelerdeki sosyoekonomik gelişmeler, nüfustaki yaşlanma oranları ile paralellik göstermezler. Örneğin Fransa'daki yaşlı nüfus oranının \%7'lerden \%14'lere yükselmesi için 115 yıl gerekirken, Çin'de aynı oran artışı için sadece 27 yıl beklenir. Gelişmiş olan ülkeler nüfuslarının yaşlanmasından önce "refah ülkesi" şekline gelirken, gelişmekte olan ülkelerde ise refah düzeyinde somut bir yükselme görülmeden nüfus artışı görülmektedir (Kuzu vd., 2019). Gelişmekte olan ülkelerde yaşlanma durumu beraberinde aile yapısında, toplumsal cinsiyet rollerinde, göçler vb. durumlarda çeşitli değişimlere sebebiyet verebilmektedir (Coll-Planas vd., 2017). Yine bu ülkedeki genç bireylerin yeni bir işe girmek, araştırma yapmak gibi konularda başka şehirlere veya ülkelere göç etmesi, aile yapısında değişikliklere ve yaşlı kişilerin desteğe, bakıma ya da herhangi farklı bir yardıma gereksinim duyduklarında bakım verebilecek yetişmiş insan gücünün daha az olacağı öngörülmektedir (Arun, 2015).

Kinsella ve He'nin çalışmasında dünyadaki nüfusun hızla yaşlandığı 2008 yılında 65 ve üzeri yaş grubu kișilerin dünyadaki nüfusun \%7'sini oluşturmakta olduğu ve 2040 yılına gelindiğinde yaşlı nüfusun \%14'lere yükseleceği, dünyadaki yaşlı nüfusunun her ay ortalama 
870 milyon artacağı öngörülmektedir (He ve Kinsella, 2020). Şekil 1'de de görüldüğü üzere dünyada 60 yaş ve üzeri nüfusun 2015 yılına kıyasla 2050 yllında önemli ölçüde artacağı görülmektedir (Şekil 1).
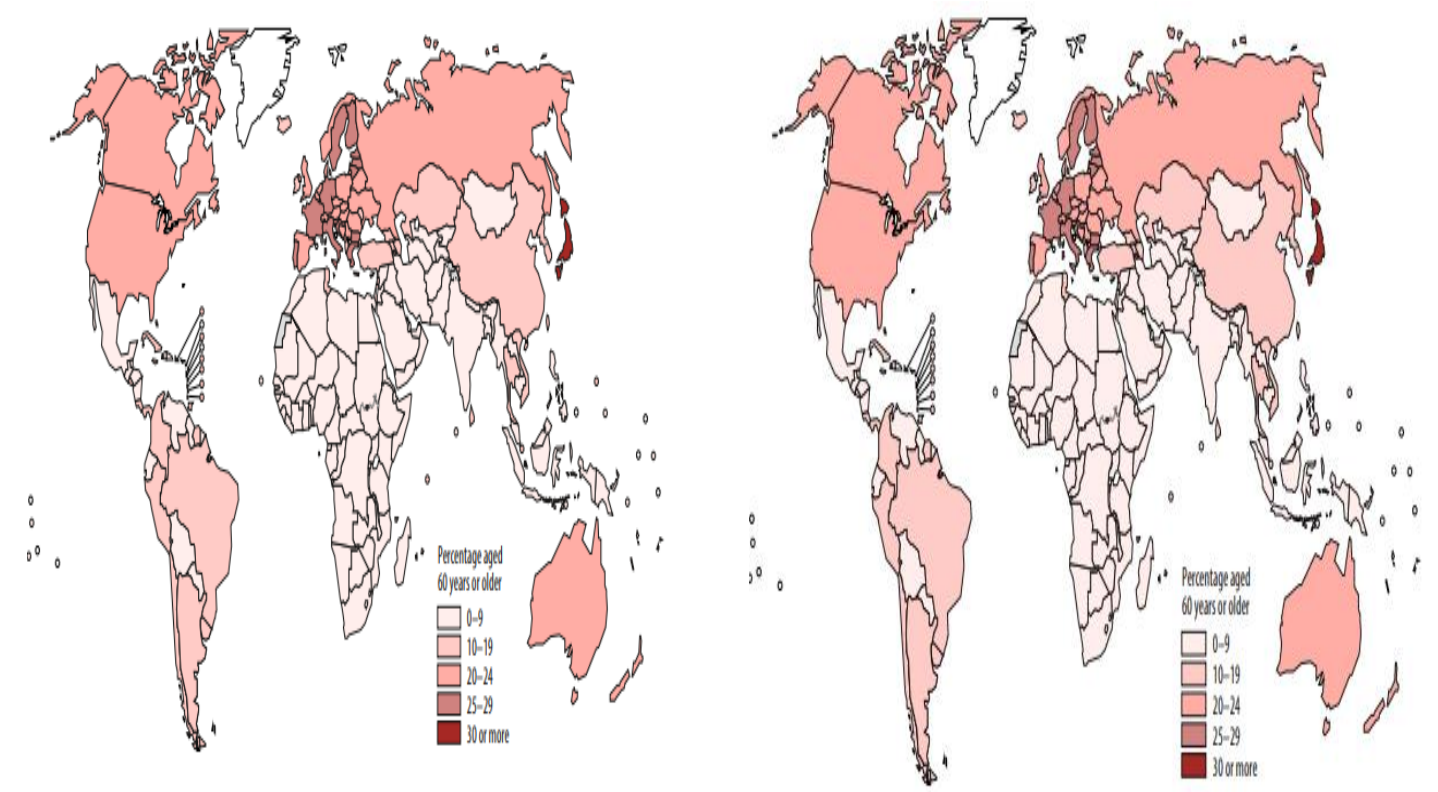

Şekil 1. Dünya'daki 60 yaş ve üzeri bireylerin sırasıyla 2015 ve 2050 yılında nüfus içindeki oranı (\%) (World Health Organization, 2021a)

Türkiye'de son yıllarda yaşlı nüfus hızla artmaya başlamış ve bunun sonucunda yaşlı nüfusun genel nüfusa oranı itibarıyla yaşlı toplumlar sınıfına dâhil olmuştur (TNSA, 2018). Ayrıca demografik dönüşüm çerçevesinde doğurganlık ve ölüm hızlarındaki düşüş de düşünüldüğünde her 10 kişiden birinin yaşlı olduğu, yaşlı nüfusun artmaya devam edeceği öngörülmekte olup bu durum kırılgan ve etkiye açık bir grup olan yaşlıların eşitsizliklere maruziyetin önleme temelli politik yaklaşımların oluşturulmasını önemini ortaya koymaktadır. Türkiye'de demografik dönüşümün üçüncü aşamasında olsa da sanayileşmiş toplumlarının gerisindedir (Şentürk, 2017). Şekil 2'de de görüldüğü gibi nüfus piramidinin tabanının daralması ve fıçı şeklini almaya başlaması nüfusun yaşlandığını göstermektedir (Şekil 2). 

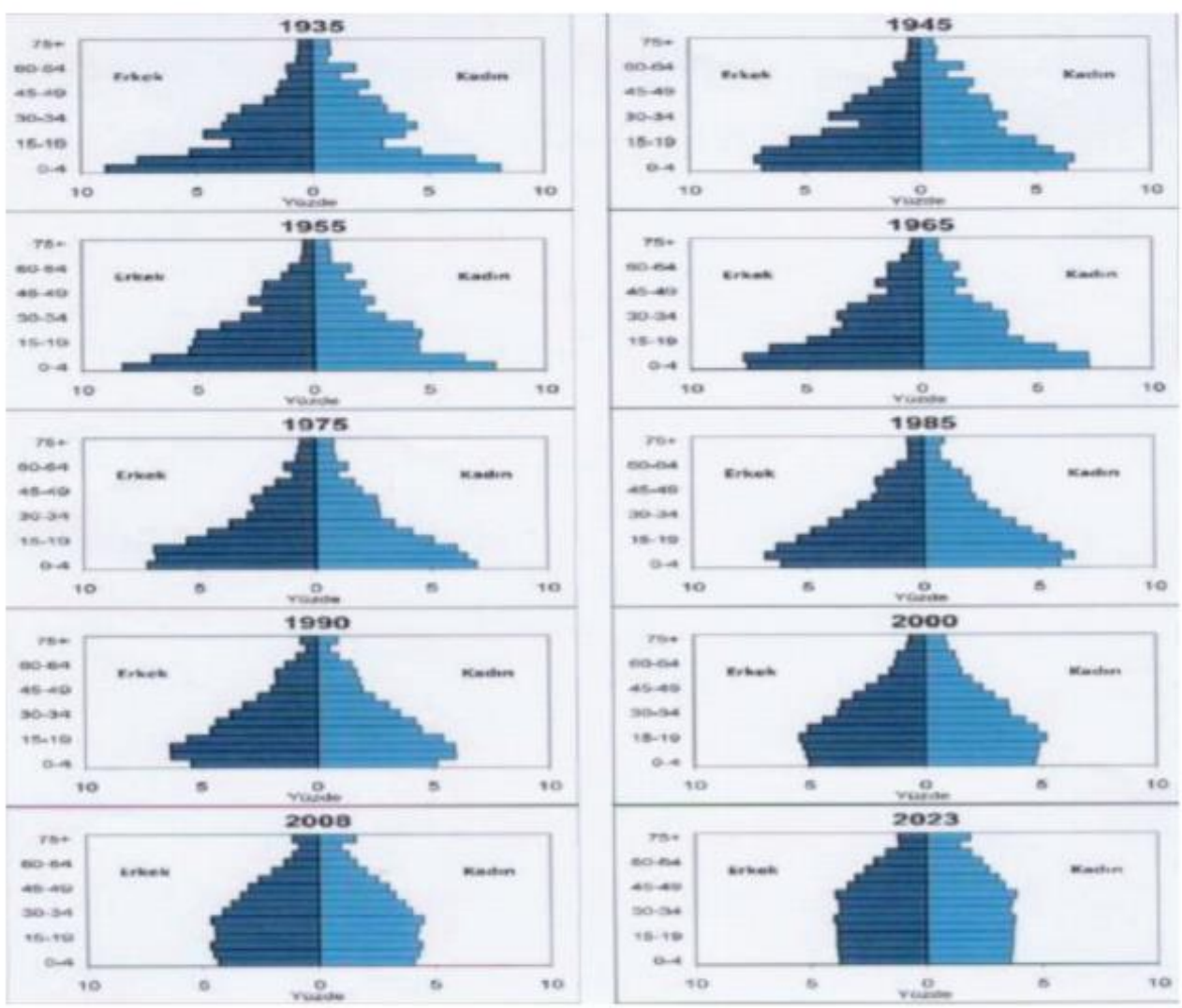

Şekil 2. Türkiye'nin Demografik Dönüşümü (T.C. Kalkınma Bakanlığı, 2019)

Görüldüğü üzere dünya ve Türkiye nüfusunun önümüzdeki on yıllarda hızla yaşlanacağı görülmektedir. Ancak buradaki anahtar soru kaçınılmaz bir durum olan yaşlılığın her birey düzeyinde sağlık ve sosyal gereksinimlerin ne ölçüde karşılanacağıdır. Nüfustaki yaşlanma, sağlıktan güvenliğe, çevreden eğitime, iş imkânlarına, sosyokültürel faaliyetlere ve aile yaşamına kadar toplumu pek çok yönde etkileme potansiyeline sahiptir.

Pek çok birey yaşlılıkta meydana gelen rahatsızlıkların kaçınılmaz bir son olduğu düşüncesine sahiptir ancak bunların birçoğu önlenebilir veya kontrol edilebilir rahatsızlıklardır (Zaninotto vd., 2020). Sosyal belirleyicilerin oluşturduğu riskler, sağlıksız yaşam tarzı, sağlık hizmetlerine erişememe gibi nedenlerle eşitsizliklere de yol açabilmektedir.

\section{Yaşlılıkta Görülen Sorunlar}

Yaşlılar, kronolojik, biyolojik ve fizyolojik olarak meydana gelen değişiklikler sonucunda daha sık hastalanırlar, daha fazla sağlık sorunlarıyla karşılaşırlar, erişkin popülasyona göre uyku problemleri daha sık görülür (Razavi vd., 2017). Yaşlılar, kronik ağrı açısından önemli bir risk grubu olduğu gibi kronik hastalıklar ve ağrı, görme, işitme kayıpları, algılanan sağlık ve sağlık hizmetlerine ulaşılabilirlik yaşlı bireylerin yaşam kalitesini çok olumsuz olarak etkiler (Güneş, 2018; Özerdoğan vd., 2018). Ağrı, yaşlı bireylerde anksiyete, depresyon, uyku bozuklukları ve hareket kısıtlılı̆̆ı, gibi sağlık sorunlarına da yol açarken tremor da yaşlılarda sık 
görülen bir semptomdur. Bir başka yaşlı sağlığı sorunu da yaşlanmayla birlikten artan ağız-diş sağlığı sorunları ve diş kayıpları olup diğer sağlık sorunları gibi yaşlının ağız sağlığı, genel sağlığı ve yaşam kalitesiyle çok yakından ilişkilidir (Güneș, 2018; Mooventhan ve Nivethitha, 2017).

Yaşlılarda bulaşıcı olmayan hastalıklarda artış görülürken aynı zamanda geriatrik sendrom, kırılganlık, düşme, osteoporoz, inkontinans, demans, depresyon, deliryum, sarkopeni, malnutrisyon gibi durumların da görülme sıklığı artmaktadır (Kosuva Öztürk ve Şahin, 2021). Yaşlılarda depresyon, ihmal, istismar ve yaşlı intiharları da önemli sorunlar olarak karşımıza çlkmakta, yaşlıların dezavantajlı gruplar içinde yer almalarıyla birlikte bu sorunlar artış da göstermektedir (Beghi vd., 2021). Yaşlıların yalnız olması, izole olması, gelir ve eğitim durumunun kötü olması gibi sosyal belirleyiciler yaşlıların mental sağlığını olumsuz etkilemektedir (Cevik vd., 2021; Wang vd., 2018). Sosyoekonomik durumun yaşlılarda mortalite, sağ kalım, herhangi bir hastalık varlığı (kronik, psikolojik, sağlık algısı), yaşam kalitesi, engelli olma durumu, mevcut sağlık davranışları, sağlık hizmetlerine erişim ve kullanım, sosyal problemler (ihmal, istismar) ile ilişkili olduğu bulunmuştur (Şimşek ve Uçku, 2012). Hollanda da yürütülen bir kohort çalışmasında yaşlıların eğitim durumu, yaşanılan yer ve psikososyal durumunun sağlıkta eşitsizliklere neden olan bileşenler olarak saptanmıştır (Hoogendijk vd., 2018). Düşmeler yaşlılarda en sık rastlanan travma türü olup düşmelere bağlı kırıklar ve ölüm meydana gelebilir ya da fonksiyon kaybıyla yaşlının yaşam kalitesi olumsuz etkilenebilir (Güner ve Ural, 2017). Göğüs ağrısı ve akut miyokart enfarktüsü yaşlılarda yaşamı tehdit eden akut sorunlar olup yaşlılar, birçok kronik hastalıkla, polifarmasi ile yaşamlarını sürdürmektedir. Görüldüğü gibi yaşlılıkta karşılaşılan kardiyovasküler hastalıklar, kanserler ve diğer risk faktörleri kırılgan, etkiye açık bir hale gelen yaşlıları eğer sosyoekonomik bakımdan da dezavantajlı iseler (kırsal bölgede yaşama, eğitim / gelir durumunun düşük olması, kadın olma, alt sosyal sınıfta olma, izole olma gibi) yaşlılarda hastalanma, ölümlülük, artmakta, yaşam kalitesi azalmaktadır (Gün, 2019).

\section{Yaşlılarda Sağlığın Korunması ve Geliştirilmesi}

Yaşlıların başat sağlık sorunları arasında bulaşıcı olmayan hastalıklar ve sosyal sorunlar yer alsa da bu iki konunun yaşlılar özelinde bir arada verildiği bir örgütlenme yapısı Türkiye'de yoktur. Sağlık Bakanlığı, kronik hastalıkları önlemek, sağaltmak, rehabilite etmek, gibi sağlık gereksinimleri boyutuyla, Aile Sosyal Politikalar Bakanlığl ve yerel yönetimler sosyal yönden iyiliklerini sağlamak amacıyla faaliyetlerini sürdürmekte, bu kapsamda yaşlıların sağlığını korumak ve geliştirmek amacıyla önleme ve kontrol programları, eylem planları, yaşlı sağlığı modülleri uygulamaya konulmaktadır (T.C. Aile Sosyal Politikalar Bakanlığı, 2007; T.C. Sağlı Bakanllğ̆, 2021). 
Yaşlı sağlığı açısından DSÖ Avrupa Bölgesi tarafından beş öncelikli alan belirlenmiştir (World Health Organization, 2021c): Bunlardan ilki düşmelerin önlenmesi olup, 65 yaş ve üzeri kişilerin \%30’u ve 80 yaş üzeri bireylerin \%65’i her yıl düşmektedirler. Ayrıca kadınlar erkeklere göre osteoporoz ve kas gücü açısından daha fazla risk altındadır. İkinci alan bedensel etkinliğin artırılmasıdır. Bu kapsamda hastalıkların önlenmesi, yaralanmaların azaltılması, mental, sosyal, bilişsel, cinsel sağlığın korunması için önerilmektedir. Üçüncü alan yaşlı bireyler için grip aşısının yapılmasıdır. Yaşlılar mevsimsel grip hastalığı dönemlerinde süreçten olumsuz etkilenmektedir. Dördüncü alan evde bakım hizmetlerinin geliştirilmesi için kamusal mekanizmaların güçlendirilmesidir. Kuşkusuz kamusal mekanizma olmaksızın bu hizmetlerin eksik olduğu bilinmelidir. Beşinci alan sağlık ve sosyal hizmet sunulan kurumlarda geriatri ve gerontoloji açısından kapasite geliştirilmesidir. Bu önceliklerin sosyal izolasyon ve toplumsal dışlanmanın önlenmesi, yaşlılara yönelik kötü muamelenin önlenmesi, demans ve uzun süren palyatif bakım hastalarını da kapsayan hizmetlerin niteliğinin artırılmasından oluşan destekleyici mekanizmalar da gereklidir.

Yaşlı sağlığının korunup geliştirilmesinde sık görülen sağlık sorunlarının tespiti ve belirleyicilerinin ortaya konması durum saptama açısından önemlidir. Bulaşıcı olmayan hastalıklar sık görülen sağlık sorunlarından olup yaş ile artış gösteren bir sorun olmalarına rağmen yaşlılığın doğal bir sonucu da değildirler. Sağlıklı yaşam biçimi davranışlarının sergilenmesiyle birlikte kardiyovasküler sorunlar, kanserler gibi birçok bulaşıcı olmayan hastalık ve obezite, sigara gibi hastalıklarla ilişkili risk faktörleri bertaraf edilmiş olur (Bilir, 2009; Ulutaşdemir, 2019). Hastalıklarla savaşımda, korunmada birincil korunma en etkili yaklaşım olup aynı zamanda eşitsizliğin azaltılmasına da katkıda bulunmaktadır. Fakat birincil korunma yöntemleri bilinse de bireylerin davranışlarına yansımaması önemli bir sorundur. İkincil korunma olarak yaşlıların erken dönemde başlıca sık görülen bulaşıcı olmayan hastalıklar bakımından erken tanısı önemlidir. Bu durum yaşlıların özellikle birinci basamakta düzenli takibi, ev ziyaretleri ve taramalar ile mümkündür. Erken tanı ile birlikte de sağaltım olduğu gibi yaşlıların yaşam kaliteleri, otonomileri de artmaktadır (Bilir, 2009). Yaşlıların hastalık farkındalığının da düşük olduğu düşünüldüğünde taramaların önemi ortaya çıkmaktadır. Bu nedenle erken dönemde tespiti mümkün olan hastalıklara yönelik taramalar yapılmalı, eğer yaşlı kırsal bölgede yaşıyorsa, kadınsa, gelir, eğitim durumu düşük ise bu grup yaşlılara ayrıca dikkat edilmelidir. Yaşlılar için sağlık hizmetlerinden yararlanmaya ilişkin bazı sorunlar vardır. Yaşlılar işitme ve görmenin zayıflaması, idrar güçlüğü gibi bazı semptomları, yaşlanmanın doğal bir sonucu olarak kabul edip sağlık hizmeti kullanamayabilirler (Bilir, 2009; Güneş, 2018). Ayrıca fizyolojik işlev gerilemesine bağlık olarak yaşlı kişi hastalık belirtilerini de tam olarak algılamayabilir. Burada eğitim düzeyinin düşük olması da algılama düzeyini olumsuz etkileyen bir faktör olarak karşımıza çıkar. Bazen de yakınmalarının farkında olan yaşlılar çeşitli 
nedenlerle sağlık hizmetinden yararlanmak istese de coğrafi ya da ekonomik ulaşılabilirliğin sınırlanması nedeniyle sağlık hizmetinden yararlanamayabilirler (Çevik, 2017). Tüm bu sorunlar toplumların yaşlılara verdiği değer, yaşlılara sunduğu olanaklar ile ilişkilidir. Üçüncül korunma hastalıktan değil hastalığın komplikasyonlarından korunmayı, rehabilitasyonu ifade eder. Yaşlılıkta sağlıklı yaşam yıllarının, yaşam kalitesinin artırılması ve ölümün ötelenmesi önemli olup, dezavantajlı yaşlılar öncelenerek sağlık ve sosyal hizmetler ile yaşlı gereksinimleri örtüştürülmelidir.

\section{Sağlıkta Eşitsizlik}

Sağllkta eșitsizlikler, sosyal, ekonomik, kültürel, siyasal nedenlerle ortaya çıkabilen, olması kabul edilemez olan ancak önlenebilir durumlardır (Şimşek ve Kılıç, 2012). Artan eşitsizlikler doğuşta beklenen yaşam süresi, maruz kalınan halk sağlığı sorunları, sağlık hizmetlerine erişim gibi birçok konuda toplumda farklılıklar yaratmaktadır (Lallo ve Raitano, 2018). Sağlıkta eşitsizlik çalışmalarında kullanılan değişkenlere bakıldığında sosyoekonomik durum, gelir, sınıf ve öğrenim durumunun ana bağımsız değişkenler olarak, risk etmenleri, algılanan sağlık, güven düzeyi ve hizmet kullanımının bağımsız değişkenler olarak hastalık, engellilik, hastalık yükü, beklenen yaşam süresi, ölüm, cinayet ve intiharın bağımlı değişken olarak kullanıldığı görülmektedir(Şimşek ve Kılıç, 2012).

Temel insan hakları içinde yer alan sağlık hakkı eşitsizliklerin derinleștiği düşünülürse ne yazık ki ütopya gibi görünmektedir. Geçmişten günümüze tartışllan eşitsizlik, özellikle AlmaAta'da ülkeler arasındaki sağlık durumunun farklı olduğu bir süreçte "Herkes için Sağllk" sloganıyla birinci basamak sağlık hizmetleri odaklı çözüm arayışı söz konusu olmuş önemli ölçüde de sağlık düzeyi göstergelerinde iyileşmeler olmuştur (Roland, 2019). Kuşkusuz buradaki başarının altında etkili bir birinci basamak sağlık hizmetinin temel sağlık hizmetlerinin kilit taşı olarak belirlenmesi ve hayata geçmesidir.

Eşitsizliği ön plana koyan en önemli belirteçler sağlık düzeyi göstergeleri olup eșitsizliğin yansımaları başlıca doğuşta beklenen yaşam süresi, anne ölüm hızı, bebek ölüm hızı, çocuk ölüm hızı gibi göstergelere yansımaktadır. Sağlıkta eşitsizliklerle ilgili bir başka belirteç de sağlık sistemi, sağlık politikaları, örgütlenme ve finansmandır. Sağlık hizmetlerinin kamu ya da özel kesim elinde sunulması başlıca risk gruplarının sağlık hizmetine erişimiyle ilişkili olup bu durumda sağlık düzeyi göstergelerini etkilemektedir (Şimșek ve Kılıç, 2012). Özel sektörün yaygın olduğu sağlık sistemlerinde yaşlıların sağlığı için daha fazla harcama yapılırken koruyucu hizmetlerin sınırlı olmasıyla da ilişkili olarak sağlık düzeyi göstergelerinin istenilen seviyede olmadığı görülmektedir (Awoke vd., 2017). Bu çerçevede sağlık sisteminin sosyal devlet ilkelerine uygun olması eşitsizlik makasını da daraltacağı görülmektedir (Demirel ve Akın, 2014). 
Sağlık harcamaları da eşitsizlikle ilgili bir başka gösterge olup Gini indeksi 2018 yılı verilerine göre Türkiye'de 0.41, İngiltere'de 0.35, Fransa'da 0.32, Almanya'da 0.31 olup gelir dağllımındaki eşitsizliğin Türkiye'de yüksek olduğu görülmektedir (World Bank, 2021). Sağlık hizmetlerinin ikinci, üçüncü basamak ağırlıklı yürütülmesi, özel eliyle sunulması, gibi faktörler hem eşitsizlikleri hem de sağlık harcamalarını artırmaktadır (Blanchet vd., 2018; Garzón-Orjuela vd., 2020). Türkiye ve Dünya'daki incelenen bazı veriler sağlıktaki adaleti ve eşitliği sağlamakta en önemli engellerin bazı sosyal belirleyiciler olduğunu göstermektedir (Pala, 2015; Şimșek ve Kılıç, 2012; Şimşek ve Uçku, 2012). Ekonomik olarak alt sosyal sınıflarda olan bireylerde göz önüne alınarak mevcut kaynakların eşit dağılımı ve vergi sisteminin de "gelire göre vergi" anlayışıyla yapılandırılması büyük önem taşımaktadır. Yine sosyal ve fiziki çevre şartlarının iyileştirilmesi için, mevcut çevre, eğitim düzeyleri, sağlık hizmetleri ve sosyal aktivitelerinde tüm toplum için eşit ve adaletli olması gerektiği vurgulanmalıdır (Victora vd., 2021).

\section{Yaşlılık ve Sağlıkta Eşitsizlikler}

İleri yaşlarda görülen eşitsizlikler tesadüfi olmayıp büyük kısmı insanların fiziksel ve sosyal ortamlarından ve bu ortamların sağlı davranışları üzerindeki etkilerinden kaynaklanmakta, çevre, içine doğulan aile, cinsiyet ve etnik köken gibi kişisel özellikler sağlıkta kümülatif eşitsizliklere yol açmaktadır(World Health Organization, 2021b). Sağlık politikaları, bu eşitsizlikleri pekiştirmek yerine azaltmak için üretilmelidir (World Health Organization, 2018). DSÖ sağlıklı yaşlanmaya yönelik olarak; yaşlı odaklı kanıta dayalı politikaların geliştirilmesini, sağlık sistemlerinin yaşlı nüfusun gereksinimleri ile uyumlu olmasını, bakım verenlerin bu sisteme entegre edilmesini, uzun süreli bakım sağlamak için sistemler geliştirilmesini, altyapı ve işgücü kapasitesinin artırılmasını, yaşlı dostu çevreler yaratılmasını, yaşlı sağlığının sürekli ölçme, değerlendirilmesini önermektedir (World Health Organization, 2021c). Türkiye'de yaşlılara yönelik hizmetler, Sağlık Bakanlığı, Aile Sosyal Hizmetler Bakanlığı, yerel yönetimler ve özel sektör tarafından sürdürülmekte olup 2020 yılında huzur evi sayısının 153, kapasitesinin 15.527, bakılan kişi sayısının 13.925 olduğu, bakanlığa bağlı huzurevlerinin \%36'lık kısmı, özel sektöre bağlı huzurevlerinin ise \%58'lik kısmı oluşturduğu görülmektedir. 2020 yılında kamu ve özel sektöre ait huzur evlerinde 27.372 kişinin bakımı gerçekleşmiş, 730.301 kişi yaşlı maaşı almış ve yaşlıların iş gücüne katılım oranı \%12.2'dir. Yaşlı kadın nüfusun \%17'si, erkek nüfusun \%13.5'i toplamda yaşlı nüfusun \%15.5'i yoksuldur (Tablo 1) (Aile ve Sosyal Hizmetler Bakanlığı, 2020). 


\section{Tablo 1}

Cinsiyete göre yaşlı nüfusun yoksulluk oranı, 2013-2017

\begin{tabular}{|c|c|c|c|c|c|c|}
\hline \multirow{2}{*}{ Cinsiyet } & \multirow{2}{*}{ Yaş grubu } & \multicolumn{5}{|c|}{ Yll } \\
\hline & & 2013 & 2014 & 2015 & 2016 & 2017 \\
\hline \multirow{2}{*}{ Kadın } & $65+$ yaş & 18.2 & 18.2 & 18.6 & 17.0 & 17.0 \\
\hline & Toplam & 22.8 & 22.2 & 22.0 & 21.6 & 20.7 \\
\hline \multirow{3}{*}{ Erkek } & $65+$ yaş & 17.4 & 18.3 & 17.8 & 14.7 & 13.5 \\
\hline & Toplam & 22.0 & 21.4 & 21.7 & 20.8 & 19.6 \\
\hline & $65+$ yaş & 17.9 & 18.3 & 18.3 & 16.0 & 15.5 \\
\hline Toplam & Toplam & 22.4 & 21.8 & 21.9 & 21.2 & 20.1 \\
\hline
\end{tabular}

Türkiye'de 2000'li yılların başından itibaren sağlık hizmetlerinde yaşanan dönüşüm ile birlikte aile hekimliği uygulaması, sosyal güvenlik reformu, Sağlık Bakanlığının teşkilat yapısının değişimi gibi örgütlenme, finansman boyutuyla önemli değişiklikler meydana gelmiştir. Sağlıkta Dönüşüm Programı olarak adlandırılan süreçle birlikte birinci basamak hizmet sunumu değişmiş, sosyal güvenlik sistemi ve Sağlık Bakanlığının teşkilat yapısında önemli değişikler olmuştur (Yasar, 2011). Türkiye'de dönüşüm çerçevesinde sağlık hizmetleri organizasyonu iki süreçle ifade edilmektedir. İlk olarak kamu-özel ortaklık uygulamasının örneklerinden olan şehir hastaneleri ve entegre hastaneler kurulurken diğer yandan aile hekimliği uygulamasıyla sağlık hizmetlerinde birinci basamak hizmeti güçlendirmeyi ve kaliteyi arttırmanın amaçlandığı belirtilmektedir. Bu olay özellikle birinci basamaklara olan erişimi artırmakta olup, öte yandan özel sektör anlayışını sağlık sektörüne taşıyarak eşitsizlik riskini arttırmaktadır. Sağlıkta dönüşüm adı altında yapılan bu yeniliklerin eşitsizliklere yönelik net bir sonucu ifade edilememektedir. Bazı çalışmalara göre hizmet erişimi açısından olumlu etkilerinin olduğu kabul edilirken, diğer yandan kalite açısından hala eşitsizliklerin olduğu ortaya konmaktadır (Şimşek ve Kılıç, 2012). Türkiye'de Şırnak, Hakkari, Van, Ağrı illerinde 65 yaşını göremeden ölenlerin oranı \%45-60 arasında değişirken, Gümüşhane, Burdur, Çankırı, Sinop illerinde bu oran \%18-20 arasında değişmektedir (Pala, 2015). Özellikle içinde bulunduğumuz COVID-19 pandemisinde aile hekimlerinin nüfuslarına kayıtlı yaşlı bireyleri değerlendirirken hastalığın bulaşmasını önleme, erken tanı, tedavi ve izlem aşamalarına yönelik çok yönlü bakış açısı ile yaklaşımları önemlidir (Karaca, 2020). Yaşlıların birinci basamakta izleminin gerçekleştirilmesi olası tehlikelerin saptanarak çözüm yollarının bulunması, birincil, ikincil koruma anlamında önemlidir. Ancak aile hekimliği sisteminde iki kişiden oluşan bir ekip olması, ev ziyaretlerini çok sınırlı olması, performansa dayalı ödemenin hizmet sunumunu şekillendirmesi nicel bir artış olsa da nitel bir artışı mümkün kılmamaktadır (Cevik ve Kilic, 2018). Nitekim Özdemir ve Koçoğlu'nun Sivas'ta yürüttüğü çalışmada aile hekimliği sisteminin istenilen ölçüde etkili olmadığı, performansa dayalı bazı hizmetlerde istenilen başarılar yakalansa bile hala eksikliklerinin olduğunu, esas uygulanmak istenilen sistemin uygulanamadığını ve toplumu 
memnun edecek bir sisteme adapte edildiği görülmektedir (Özdemir ve Koçoğlu, 2019). Yetişkin bireyler ve çocuklar gibi, yaşlılarında birinci basamak sağlık hizmetinden eşit faydalanma ve bu hizmete erişebilme hakkına sahiptir. Bu sebeple yaşlı bakım hizmetlerinde, çalışan eğitimini ve yaşlı bireylerin ihtiyaçlarını karşılayacak bazı düzenlemelere gereksinim vardır (Tekingündüz vd., 2016).

\section{SONUÇ VE ÖNERÍLER}

Türkiye'de ve dünyada sağlıkta eşitsizlikler giderek önem kazanan önemli bir halk sağlığı sorunudur. Özellikle yaşlıların bu eşitsizliklerden korunması, yalıtılması gerekmektedir. Kırılgan grupların başında gelen yaşlıların sağlığına ilişkin dezavantajlar özellikle COVID-19 pandemisi döneminde derinleşmiştir. Artan yaşlı nüfusu ve buna bağlı olarak bulaşıcı olmayan hastalıklar yaşlılara yönelik sağlık ve sosyal hizmetleri öncelikli hale getirmiştir. Bu nedenle yaşlıların yaşamlarına en üst düzeyde devam edebilmesi için geliştirilmiş ve kapsamı genişletilmiş bir şekilde yeni sağlık politikaları uygulanmalı ve gerekli şartlar sağlanmalıdır. Yaşlanan nüfusun artışı, sağlığın bozulmasına, bu durum da sağlık harcamalarının artışına, sağlık hizmet kullanımının artmasına neden olmaktadır. Ekonomik açıdan kamuya bağımlı ve herhangi bir bulaşıcı olmayan hastalığı olan bireyler diğer yaşlı grubundan ayrı bir şekilde ele alınmalıdır. Yaşlanma süreci kaçınılmazdır ancak bu süreç sağlıklı, etkin ve kaliteli bir şekilde olabilir. Bu dönem içerisinde yaşam kalitesinin artırılması, sağlıklı bir yaşlanma ile ilgili çeşitli stratejilerin geliştirilmesi, toplum sağlığını geliştirmede önemli bir seçenektir. Bu nedenle genel politikalar dışında, yaşlı kesime yönelik olan özel politikalar geliştirilmeli ve en kısa zamanda uygulanmalıdır. Kişisel ve toplumsal alanlarda sağlıklı bir yaşlanmanın önemliliği ifade edilmeli, yaşlı sağlığına yönelik farkındalığı artırmak amacıyla eğitimler düzenlenmelidir. Diğer yandan eşitsizlikleri ortadan kaldırma amaçlı, yaşlı bireylerin dahil oldukları sağlık sorunları, sosyal sorunlar belirlenmeli, sağlı hizmetlerine ulaşmadaki problemleri incelenmeli, değerlendirilmeli, çözüm yolları bulunmalıdır. Sosyal devlet ilkeleri ve halk sağlığı politikalarının her noktada etkin biçimde uygulanması yaşlılar düzeyinde ve toplum düzeyinde eşitsizlikleri azaltacaktır. Sağlık politikaları tekrar gözden geçirilmeli ve yaşlı bireylere yönelik koruyucu sağlık hizmeti, yaşlıların birinci basamakta nitelikli izlemi üzerinde durulmalıdır. Sağlık alanında tüm bireylere eșit şartlar tanınmalı ve gereksinim sahibine daha fazla hizmet görüşüyle sağlık hizmetleri yeniden yapılandırılmalıdır. Eşitsizliklere yönelik sağlığı etkileyen faktörler içerisinden özellikle sosyal belirleyicilere, koruyucu sağlık hizmetlerine, toplumsal farkındalığa odaklanılmalıdır. Yaşlılar düşünülerek sektörler arası işbirliği çerçevesinde uygun yaşam alanları oluşturulmalı, toplumdaki sosyal sınıfa bağlı dezavantajlar ortadan kaldırılmalıdır. 


\section{KAYNAKÇA}

Aile ve Sosyal Hizmetler Bakanlığı. (2020). Engelli ve Yaşlı İstatistik Bülteni. https://www.ailevecalisma.gov.tr/media/40734/istatistik-bulteni-subat2020.pdf

Arun, Ö. (2015). Eşitsizliklerin kavşağında: çağdaş Türkiye'de yaşlılık ve sağlık. In D. Alptekin (Ed.), Hasta Toplum (pp. 125-144). Nobel yayınları.

Awoke, M. A., Negin, J., Moller, J., Farell, P., Yawson, A. E., Biritwum, R. B., \& Kowal, P. (2017). Predictors of public and private healthcare utilization and associated health system responsiveness among older adults in Ghana. Global health action, 10(1), 1301723. https://doi.org/10.1080/16549716.2017.1301723

Beghi, M., Butera, E., Cerri, C. G., Cornaggia, C. M., Febbo, F., Mollica, A., Berardino, G., Piscitelli, D., Resta, E., Logroscino, G., Daniele, A., Altamura, M., Bellomo, A., Panza, F., \& Lozupone, M. (2021). Suicidal behaviour in older age: A systematic review of risk factors associated to suicide attempts and completed suicides. Neuroscience \& Biobehavioral Reviews, 127, 193-211. https://doi.org/10.1016/i.neubiorev.2021.04.011

Bilir, N. (2009). Yaşlılıkta sağlığın korunması ve koruyucu hekimlik. http://ekutuphane.teb.org.tr/pdf/tebakademi/geriatri 2009/6.pdf

Blanchet, T., Clarke, R., Czajka, L., Estévez-Bauluz, L., Gethin, A., \& Lenders, W. (2018). World inequality report. https://wir2018.wid.world/files/download/wir2018-summaryturkish.pdf

Cevik, C., \& Kilic, B. (2018). Change from health center to family physician period in the Turkish health system: A qualitative study. The International journal of health planning and management, 33(4), e1022-e1036. https://doi.org/https://doi.org/10.1002/hpm.2580

Cevik, C., Ozdemir, R., Koran, N., \& Agın, A. (2021). Prevalence and risk factors for elder abuse: A community-based cross-sectional study from North West Turkey. Current Psychology, 18. https://doi.org/10.1007/s12144-021-01423-1

Coll-Planas, L., Nyqvist, F., Puig, T., Urrútia, G., Solà, I., \& Monteserín, R. (2017). Social capital interventions targeting older people and their impact on health: a systematic review. $J$ Epidemiol Community Health, 71(7), 663-672. https://doi.org/10.1093/geroni/igx004.781

Çevik, C. (2017). Yaşlıların sağlık hizmetine erişimi. Turkiye Klinikleri J Public Health Nurs-Special Topics, 3(3), 165-171.

Demirel, T., \& Akın, B. (2014). Sağlıkla ilişkili olarak sosyal adalet, eşitlik ve hemşirelik. DEUHYO, $7(3), 238-245$.

Garzón-Orjuela, N., Samacá-Samacá, D. F., Angulo, S. C. L., Abdala, C. V. M., Reveiz, L., \& EslavaSchmalbach, J. (2020). An overview of reviews on strategies to reduce health inequalities. International journal for equity in health, 19(1), 1-11. https://doi.org/10.1186/s12939020-01299-w

Gün, İ. (2019). Geriatriye disiplinlerarası yaklaşım In Geriatride sağlık eșitsizlikleri.

Güner, S. G., \& Ural, N. (2017). Yaşlılarda düşme: Ülkemizde Yapılmış tez çalışmaları kapsamında durum saptama. İzmir Katip Çelebi Üniversitesi Sağlık Bilimleri Fakültesi Dergisi, 2(3), 915.

Güneş, G. (2018). Yaşlılıkta kronik ve akut sağlık sorunları. In B. Duy (Ed.), Temel gerontoloji (Vol. 5, pp. 91-105). Anadolu Üniversitesi.

He, W., \& Kinsella, K. (2020). Global aging in the new millennium (Vol. 27). University of South Carolina. 
Hoogendijk, E. O., Heymans, M. W., Deeg, D. J., \& Huisman, M. (2018). Socioeconomic inequalities in frailty among older adults: results from a 10-year longitudinal study in the Netherlands. Gerontology, 64(2),

157-164. https://doi.org/https://doi.org/10.1159/000481943

Karaca, S. (2020). Pandemide birinci basamak bakıș açısı ile yaşlı izlemi. Klinik Tıp Aile Hekimliği, 12(3), 92-97.

Kosuva Öztürk, Z., \& Şahin, S. (2021). Yaşlılarda sık görülen sağlık sorunları. In R. Uçku \& H. Şimşek (Eds.), Türkiye Klinikleri Halk Sağlı̆̆ı Özel Konular (pp. 22-27). Türkiye Klinikleri.

Kuzu, A., Aydın, C., Yıldız, M., Erik, H. E., Keskinkılıç, H. G., Aslan, D., \& Şengelen, M. (2019). Dünya sağlık örgütü Avrupa Bölgesi'nde yaşlanma ile ilgili seçilmiş bazı ölçütlerin değerlendirilmesi. STED, 28(1), 17-27. https://doi.org/10.17942/sted.378109

Lallo, C., \& Raitano, M. (2018). Life expectancy inequalities in the elderly by socioeconomic status: evidence from Italy. Population health metrics, 16(1), 7. https://doi.org/10.1186/s12963-018-0163-7

Marmot, M. (2017). Social justice, epidemiology and health inequalities. European journal of epidemiology, 32(7), 537-546. https://doi.org/10.1007/s10654-017-0286-3

Mooventhan, A., \& Nivethitha, L. (2017). Evidence based effects of yoga practice on various health related problems of elderly people: A review. Journal of bodywork and movement therapies, 21(4), 1028-1032. https://doi.org/10.1016/i.jbmt.2017.01.004

Özdemir, M. E., \& Koçoğlu, F. (2019). Sivas ilinde aile hekimliği modelinin değerlendirilmesi. Ahi Evran Tip Dergisi, 3(2), 59-65.

Özerdoğan, Ö., Yüksel, B., Çelik, M., Oymak, S., \& Bakar, C. (2018). Yaşlılarda yaşam kalitesini etkileyen faktörler. Türkiye Halk Sağlığı Dergisi, 16(2), 90-105. https://doi.org/10.20518/tjph.458209

Pala, K. (2015). Sağlıkta eşitsizlikler. https://doi.org/10.13140/RG.2.2.15080.11523

Petrovic, D., de Mestral, C., Bochud, M., Bartley, M., Kivimäki, M., Vineis, P., Mackenbach, J., \& Stringhini, S. (2018). The contribution of health behaviors to socioeconomic inequalities in health: a systematic review. Preventive medicine, 113, 15-31. https://doi.org/10.1016/i.ypmed.2018.05.003

Pickersgill, M. (2020). Pandemic Sociology. Engaging science, technology, and society, 6, 347-350. https://doi.org/10.17351/ests2020.523

Razavi, S., Razavi, M., \& Pirhosseinlou, M. (2017). A preventive approach to elderly people health problems. J Gerontol Geriatr Res, 6(450), 2. https://doi.org/10.4172/21677182.1000450

Roland, M. (2019). 40 years on. Has the vision of Alma-Ata been realized? Cadernos de saude publica, 35, e00212218. https://doi.org/10.1590/0102-311x00212218

Şentürk, S. (2017). Avrupa birliği ve Türkiye'nin sorunu yaşlılık. Ayrıntı Dergisi, 5(53), 45-50.

Şimşek, H., \& Kılıç, B. (2012). Sağlıkta eşitsizliklerle ilgili temel kavramlar. Türkiye Halk Sağlığı Dergisi, 10(2), 116-127. https://doi.org/10.20518/tjph.173070

Şimşek, H., \& Uçku, R. (2012). Sağlıkta eşitsizlikler ve yaşlılık. In D. Aslan \& M. Ertem (Eds.), Yaşlı sağlı̆̆ı sorunlar ve çözümler (pp. 12-17). Palme Yayıncılık.

T.C. Aile Sosyal Politikalar Bakanlığı. (2007). Türkiye'de yaşlıların durumu ve yaşlı sağlığı eylem planı. $\quad$ https://ailevecalisma.gov.tr/media/33628/turkiyede-yaslilarin-durumu-veyaslanma-ulusal-eylem-plani.pdf

T.C. Kalkınma Bakanlığı. (2019). Yaşlanma 2014-2018. https://sbb.gov.tr/wpcontent/uploads/2018/10/10 Yaslanma.pdf

T.C. Sağlık Bakanlığı. (2021). Yaşlı sağlı̆̆ı. https://sbu.saglik.gov.tr/Ekutuphane/YayinAra 
Tekingündüz, S., Kurtuldu, A., \& Türkkan, I. (2016). Sağlık hizmetlerinde eşitsizlik ve etik. Aksaray Üniversitesi Íktisadi ve İdari Bilimler Fakültesi Dergisi, 8(4), 32-43.

TNSA. (2018). Türkiye Nüfus Sağlı Araştırması 2018. http://www.hips.hacettepe.edu.tr/tnsa2018/rapor/TNSA2018 ana Rapor.pdf

Tufan, İ. (2016). Antik çağ’dan günümüze yaşlılık ve yaşlanma. Nobel akademik yayıncılık.

TUIK. (2021). Hayat tabloları, 2017-2019. https://data.tuik.gov.tr/Bulten/Index?p=HayatTablolari-2017-2019-33711

Ulutaşdemir, N. (2019). Yaşlı bireylerde sağlığın korunması ve geliştirilmesi (Ü. Sevil \& V. Bayram Değer, Eds.). Güven Plus Grup.

United Nations. (2021). Department of economic and social affairs ageing. https://www.un.org/development/desa/ageing/news/2018/04/health-inequalities-inold-age/

Victora, C. G., Leventhal, D. G., da Silva, I., Vidaletti, L. P., Armenta-Paulino, N., \& Barros, A. (2021). Delivery channels and the magnitude of socioeconomic inequalities in coverage of RMNCH interventions: analysis of 36 cross-sectional surveys in low-and middle-income countries. SSRN Electronic Journal. http://dx.doi.org/10.2139/ssrn.3773516

Wang, J., Mann, F., Lloyd-Evans, B., Ma, R., \& Johnson, S. (2018). Associations between loneliness and perceived social support and outcomes of mental health problems: a systematic review. BMC psychiatry, 18(1), 1-16. https://doi.org/10.1186/s12888-018-1736-5

World Bank. (2021). Gini index (World Bank estimate). https://data.worldbank.org/indicator/SI.POV.GINI

World Health Organization. (2018). Ageing and health. https://www.who.int/news-room/factsheets/detail/ageing-and-

health\#: :text=Between $\% 202015 \% 20$ and $\% 202050 \% 2 C \% 20$ the, $\% 2$ D $\% 20$ and $\% 20 \mathrm{mid}$ dle\%2Dincome $\% 20$ countries.

World Health Organization. (2021a). Ageing. https://www.who.int/healthtopics/ageing\#tab=tab 1

World Health Organization. (2021b). Health inequities and their causes. https://www.who.int/news-room/facts-in-pictures/detail/health-inequities-and-theircauses

World Health Organization. (2021c). Strategy and action plan for healthy ageing in Europe, 20122020. https://www.euro.who.int/ data/assets/pdf file/0008/175544/RC62wd10Rev1Eng.pdf

Yasar, G. Y. (2011). Health transformation programme'in Turkey: an assessment. The International journal of health planning and management, 26(2), 110-133. https://doi.org/10.1002/hpm.1065

Zaninotto, P., Batty, G. D., Stenholm, S., Kawachi, I., Hyde, M., Goldberg, M., Westerlund, H., Vahtera, J., \& Head, J. (2020). Socioeconomic inequalities in disability-free life expectancy in older people from England and the United States: a cross-national population-based study. The Journals of Gerontology: Series A, 75(5), 906-913. https://doi.org/10.1093/gerona/glz266 


\section{EXTENDED ABSTRACT}

In general, health tends to deteriorate as people age. However, underlying age-related health deterioration is inequalities. Although aging is a condition involving biological changes, situations such as isolation, loneliness, and social unhappiness may also occur due to exposure to external risks such as malnutrition, sedentary lifestyle, and loss of close relatives. The proportion of the elderly population was 1 billion in 2019 and this number is expected to increase to 1.4 billion in 2030 and 2.1 billion in 2050. In addition, social determinants such as genetic factors, environmental factors, access to health services, occupation, income, education level also affect the health of the elderly. These factors are also associated with inequalities that reflect avoidable and unacceptable situations. In other words, inequalities encountered in the field of aging in health, the status, gender, socioeconomic status of the elderly, as well as attitudes based on ageism and inadequate policies cause inequalities for the elderly. Population aging around the world adds more urgency to age inequalities. Life expectancy and healthy life expectancy are increasing for both men and women. However, as the incidence of health problems increases with age, the time spent in good health decreases. The lower a person's social status, the more likely they are to enter old age in poor health and die younger than people from higher social classes. Along with the impact of lifetime exposure to the harmful effects of inequality, a significant proportion of older people are affected by the damaging impact of living in poverty. As a matter of fact, despite the increasing elderly population in many countries, a significant group cannot access adequate services due to the lack of health and social services for the elderly. In addition, in working life, the elderly generally work in low-paid jobs and try to survive with limited income. Social determinants such as being alone, being isolated, poor economic status and poor educational status affect the mental health of the elderly negatively. While there is an increase in non-communicable diseases in the elderly, the rate of conditions such as frailty, falls, osteoporosis, incontinence, dementia, depression, delirium, sarcopenia, malnutrition that cannot be defined as geriatric syndrome, that is, disease, but which can impair quality of life and increase morbidity and mortality, is also on the rise. Depression, neglect, abuse and elderly suicides are also important problems in the elderly, and they increase with the elderly being among the disadvantaged groups. Although there is a positive relationship between non-communicable diseases and old age, with the display of healthy lifestyle behaviors, many non-communicable diseases such as cardiovascular problems, cancers and risk factors associated with diseases such as obesity and smoking are eliminated. In cases where health services cannot be provided at low cost in the universal framework, they are left alone with inequalities in places where primary health care services are not provided with quality. In cases where primary health care service is not provided effectively, elderly people, especially in developing countries, are left alone in struggling with their health and social problems, mainly in 
rural areas. It is limited to the elderly who are addicted, who have difficulty in carrying out activities of daily living, those who live in areas with poor transportation infrastructure, and only the elderly. The elderly are also faced with situations such as stigma, neglect and abuse, and when factors such as dementia are accompanied, the quality of the health care they receive may be adversely affected. In addition to the inequalities caused by not accessing health services, the elderly also face inequalities depending on social determinants such as gender, income level and class. While being old increases conditions such as chronic diseases and limitation of activities of daily living, discrimination based on gender, age and class deepens inequalities even more. Policies should facilitate the access of the elderly to health and social services, awareness should be raised in the active aging process, health literacy should be improved, their autonomy over their health should be increased, and this whole process should be supported by primary health care services.It is necessary to develop elderly-oriented evidence-based policies, to ensure that health systems are compatible with the needs of the elderly population, to integrate caregivers into this system, to develop systems to provide long-term care, to increase infrastructure and workforce capacity, to create elderly-friendly environments, and to continuously measure and evaluate elderly health.

Among the factors affecting health regarding inequalities, especially social determinants should be focused, the importance given to preventive health services and the awareness of the society towards the elderly should be increased. 